\title{
The endangered subject of quality Visual Art education
}

\begin{abstract}
Quality and meaningful Visual Art education provides opportunities for learning and holistic development to all children at school. Research projects in this regard highlight the problems that teachers experience in this field. The contribution of higher education in the training of educators to provide for teachers in Visual Art education is important. Curricula of four local and one overseas university for the BEd training in the Arts are compared and discussed. The importance of literacy and numeracy at school level is not disregarded, but the fact that visual literacy is an important part of being literate is emphasised. The current shortage of well-trained Visual Art educators is a challenge. Overcoming this challenge will provide all members of future generations in schools with the learning opportunities that are available through quality Visual Art education. The impact of several reviews of the South African Educational system and the effect thereof on Visual Art education are discussed.
\end{abstract}

Keywords: quality Visual Art, learning opportunities, teacher training, primary education, curricula, visual literacy, case study research, educational change, curriculum review

Georina Westraadt, Cape Peninsula University of Technology.

E-mail:westraadtg@cput.ac.za.

South African Journal of Childhood Education | 2011 1(2): 158-192 | ISSN: 2223-7674 | \ UJ

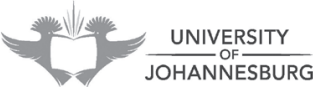




\section{Introduction}

Quality and meaningful Visual Arts education provides numerous opportunities for learning and holistic development to all children at school. It is an important tool for rich and varied learning. In many schools the teaching of Visual Art poses problems and challenges to teachers.

The impact of three reviews during the past decade of the curriculum for South African schools by the Department of Education (DoE) has placed pressure on the quality of Visual Arts education. Higher Education Institutions (HEIs) are to provide for the training of Visual Arts teachers to teach quality Art education to all learners in schools.

\section{Background}

With a new government ruling since 1994 a new National Curriculum (C2005) replaced the former curriculum rooted in Outcomes Based Education (OBE). It soon became clear that this curriculum was unsuccessful and it was reviewed by a task team appointed by the minister of education. A revised curriculum called the Revised National Curriculum Statement (RNCS) was adopted in schools in 2002. As part of this curriculum Visual Art was grouped under the learning area Arts and Culture. Arts and Culture was one of eight learning areas forming the compulsory programmes in the General Education and Training Band (primary schooling).

A new minister of education announced in 2008 in parliament that C2005 had to be reviewed again as poor school exit level results and outcomes of several research projects revealed dismal performance in literacy and numeracy of children in South African schools.

A task team conducted the review and tabled a report in 2009. A new National Curriculum was drafted in September 2010, to be implemented and phased-in from 2012 onwards. Teachers in South African schools are facing the third curriculum review in one decade.

\section{C2005 and Art education in the primary school}

Approximately $80 \%$ of teachers currently in practice in South African schools did not have formal training in OBE. Teachers already in the field at the inception of C2005 were retrained during school holidays to enable them to follow the new curriculum. It was widely expressed that the short training sessions offered during school holidays were not adequate (Rademeyer, 2009, p. 8).

For the Intermediate Phase (Grades 4-6) the one-week of compulsory training in OBE was offered to teachers prior to the introduction and implementation of the new curriculum. The first half of this training was dedicated to the principles of OBE, and the second half of the week was learning area specific. Generalist teachers in the primary school had to choose which learning area training sessions they would attend. 
Teachers who selected to receive training in the Arts and Culture learning area were not necessarily the teachers who eventually taught the integrated four disciplines, namely Dance, Drama, Music and Visual Art as this learning area was generally bestowed on teachers not for their interest, skill or expertise, but for their free periods on the timetables. Launched in April 1997, C2005, instead of heralding a brighter educational future for all, brought educators into a quagmire of poorly understood curricular dreams and promises that were almost impossible to fulfil in a regular classroom (Johnson, 2007, p. 2).

Although huge amounts of money had been spent on implementing the then new curriculum, school visits have indicated that lesson planning was superficial, and because teachers did not have subject discipline knowledge, they were not able to make assessment judgments (Western Cape Education Department: Tradeworld reference Ed 15236). In many of the so-called under-achieving schools identified by the Western Cape Education Department Arts and Culture was not offered at all.

Several projects have been offered by various non-government organisations and by the Western Cape Education Department Directorate for Curriculum Development, for in-service training in Arts and Culture, especially with regards to the 'specific pathways' for the Senior Phase (Grades 7-9) and 'focus schools' for Arts and Culture. These were presented as workshops and planning sessions. Unfortunately, several of these projects were not accessible for all educators, while a number of teachers, who have attended, reported that their teaching of Arts and Culture hardly improved through attendance of the workshops (Johnson, 2007, p. 5).

During 2008 available funding was implemented by the Western Cape Education Department to improve the quality of Arts education for under-achieving schools in the rural areas by offering skills building workshops (Western Cape Education Department: Tradeworld Reference ED 15236). The main need in the Intermediate Phase learning area, Arts and Culture, was the training of teachers to implement the curriculum. The vast majority of teachers did not have a background in the Arts, whereas some may have background or talent in only one of the four Art forms, namely Dance, Drama, Music or Visual Art.

Whenever there is change, there seems to be uncertainty. There are similarities in the uncertainties that are presently experienced in Arts education in South Africa, the UK, Australia and the USA. Various publications address concerns amongst Arts educators pertaining to good practice after a curriculum review. Uncertainty leads to problems amongst practitioners. General problems that are reported are the lack of specialised teachers and funds, and a lack of vision and knowledge of the educational potential of the Arts. Teachers in the UK comment on their vulnerability in teaching Art and the little time allocated to Art teaching, leading to slow development in the expressive subjects (Jolley et al., 2004, p. 562). Snow et al. (2005, p. 18) explore the lack of an intellectual framework for teachers and administrators in the USA to explain the importance of the subject. In addition, there is a lack of confidence that teachers experience in teaching the subject. Low teaching morale, financial cutbacks and over- 
sized groups with little resources are problems that are experienced in schools in Australia (Wright, 2003, p. 29). Educators have much to learn in presenting Art and its cultural diversity. Advisory materials are often limited, especially for non-Western modes of analysis. The real world of Art and Visual culture is about challenging and questioning and it often runs against the grain of generalist teachers. Arts educators have much to learn in terms of how they present Art, and its cultural diversity, to their pupils and students (Hatton, 2003, p. 362, 367).

A case study research project was conducted in the Western Cape during 2006. The purpose of the study was to investigate how and if Visual Art offered opportunities for learning in the primary schools selected for the case studies.

\section{Case study research}

During 2006, case studies were conducted in schools in the Western Cape Province to investigate the facilitation of learning opportunities through Visual Art.

The methodology for this study suggested a purposive sampling of quality rich cases. Four schools were selected after consultation with the subject advisor for Arts and Culture at the Educational Management District Council for the Wine land region, as well as adjudicators for the children's Art section of the Tygerberg Eisteddfod. Close proximity to the Wellington Campus was a consideration for selection.

The findings after the case study visits can be briefly summed up as follows:

\section{Three of the four cases visited}

Experienced, specialist-trained Arts educators were employed to teach Visual Art. In one case there were two Visual Arts educators, one for Foundation Phase and the other for Intermediate/Senior Phase. Every learner in these three cases participated in Visual Art activities for two periods (one hour), per cycle. Learners could participate in extra-curricular Visual Arts programmes after school hours as well.

The evidence documented for these three cases provided evidence of a rich variety of learning opportunities: Multi-literacy was addressed, visual learning occurred, and aural learning was evident. The introduction of every new project started with an explanation and sometimes the demonstration of a technique, thus combining the visual and the aural. Several projects provided kinaesthetic experiences due to the variety of media. Although the majority of the work in these cases dealt with the creation of artwork, visual literacy was addressed by the fact that, apart from the practical work, Art appreciation was done in the form of assignments and there was some evidence of work in reflection and appreciation. Intra-personal, interpersonal and spiritual intelligences were shaped by the experiences. Mathematical intelligence was utilised.

The different ways in which children learn was observed. All of the projects allowed for individual thinking patterns. The logical-mathematical, interpersonal, intra-personal 
and naturalistic, as well as spatial intelligences benefitted from these experiences and individual learning styles were encouraged.

In the three cases mentioned above, the National Curriculum Statement for C2005 was used as a guideline only. The Art forms (Drama, Dance, Music and Visual Art) were offered discreetly, not integrated, with evidence of Visual Art and Music on the timetable. Visual Art projects were linked with general class work as far as the topics concerned.

No prescriptive manuals or publications were used, as the educators were confident and experienced in their field of teaching. The teachers were comfortable and co-operative with the researcher in their classrooms.

\section{The other case}

The teachers were responsible for the Arts and Culture of their own class. They were all generalist teachers, with no specialist training. Although there was an Art room at the school, Art lessons were conducted in their own classrooms, thus not using that facility. The timetable allowed for two separate Arts and Culture periods ( 35 minutes each) a week for all classes. Some teachers were uncomfortable with the researcher in their classrooms, and in one instance refused to accommodate the researcher although prior arrangements were made. Case study visits had to be cancelled twice because teachers were using the Arts and Culture periods to catch up on other work. During the lessons visited, no attention was given to shape, size, colours, line, composition and the other elements of Art. No appreciation or study of aesthetics was done in this case.

From this evidence it could be concluded that the richest variety of learning opportunities through Visual Art occurred in cases where Arts educators were well qualified, confident and specialists in their field. In these cases Visual Art was taught in the traditional way under the guise that the National Curriculum Statement (NCS) was followed.

In the cases where generalist class teachers who have been re-trained during the sessions offered by the Western Cape Education Department were responsible for the teaching of Visual Art, the opportunities for learning were not rich and varied, and in fact, seldom facilitated (Westraadt, 2007, p. 104).

More studies that focussed on the teachers in primary schools and their experience of the teaching of Visual Art as part of the learning area Arts and Culture were conducted and are discussed briefly in the following section.

\section{Studies taking the situation of teachers in schools in account}

In a study undertaken by Ms Sandy Johnson, senior lecturer in Arts education at Cape Peninsula University of Technology, the implementation of the Arts and Culture policy document in primary schools in the Cape Peninsula was investigated. Findings of questionnaires were coded and analysed, and then this information was used to devise an open-ended interview with four teachers who were specifically selected 
for their difference in educational sites, undergraduate training and their experience. They were asked to give a narrative account of their teaching duties, the way in which they have implemented the Arts and Culture curriculum, and their responses to this new curriculum.

Although the majority of the respondents stated that their schools taught Arts and Culture according to policy, further investigation revealed that not all of these teachers had read the documents, and that a large majority of those who claimed to have read the documents could not understand them. They were, thus, only partly able to implement them. Almost all needed assistance with understanding and implementing the principles of integration. In the Arts and Culture learning area, where children should be taught to think, to problem-solve, to value and to create, they were limited by the technical rationality of their educators. There was often a tired educator, trained to be a generalist, and battling to cope, with only two hours a week allocated for the four disciplines of the Arts and Culture curriculum. On top of that there were also the other seven learning areas, which had to be dealt with (Johnson, 2007, p. 6).

\section{Curriculum review 2009}

The problems that are experienced in the teaching of Arts and Culture can be applied generally to the other learning areas as well. These problems were evident when The South African Consortium for Monitoring Educational Quality conducted the "Third International Mathematics and Science Study", testing more than 500000 learners in 45 countries in Mathematics and Science. South African learners had the lowest average scores of any country on the continent. A "Progress in Reading Literacy Study" as well as "Monitoring Learning Achievement" carried out with Grade 4-learners in 400 primary schools in 18 African countries proved that South African learners proved to be amongst the lowest scoring in the world (Education Handbook, 2009, p. 90-91). The abovementioned tests were done in 2003, 2004, 2006 and 2008. Although there was a slight improvement, South African schools were still underperforming in literacy and mathematics when compared to other nations (Bloch, 2009, p. 66). When Parliament opened in 2009 the new minister of basic education announced that a task team had been appointed to investigate the situation in schools pertaining to the teaching of the school curriculum.

Everybody involved with education in South Africa expected a review of the curriculum in schools. The task team that was appointed by the minister of basic education investigated the nature of the challenges and problems experienced in the implementation of $\mathrm{C}_{2005}$. The panel reviewed documents and conducted interviews with teachers and unions from all nine provinces. A report from the task team was tabled in October 2009. In this report changes were recommended. These changes were widely communicated and are to be implemented within a five-year plan in three phases from 2011 to 2014. The ultimate goal of the review is to improve teaching and learning, to relieve teachers of the administrative burden of the present system and to 
consolidate the curriculum into a set of coherent documents per subject (Final Report, 2009, p. 16, 27).

\section{Curriculum review and Arts education}

Curriculum 2005 (C2005) was launched in March 1997 and implemented in phases per grades from 1998. This curriculum was reviewed in 2000 and replaced by the Revised National Curriculum Statement (RNCS) in 2002. According to the revised curriculum, Arts and Culture were to be one of eight compulsory learning areas from Grade R-9. Arts and Culture include Dance, Drama, Music and Visual Art, as well as comprehensive knowledge of the diverse cultures of South Africa.

The RNCS for C2005 offered opportunity for learning through the Arts and about the Arts. Practical work, as well as appreciation (reflecting) and visual literacy were possible through the learning outcomes. Art forms of various cultures were to be studied (Western Cape Provincial Arts and Culture Task Group, 1995, p. 9-11). During the initial planning by the Western Cape Provincial Arts and Culture Task Group, Gardner's (1983) theory of multiple intelligences, which makes provision for multiple ways of learning and knowledge acquisition, was a source. The kind of learner that was envisaged was one with values, a lifelong learner who would be confident, independent, literate, numerate, multi-skilled and compassionate, with respect for the environment and the ability to participate in society (RCNS, 2002, p. 3). The studies that were conducted at schools proved that this ideal was only achieved in isolated cases.

The final report presented by the review task team in October 2009 proposed major changes with regards to Arts and Culture. In the Foundation Phase the subject Arts and Crafts replaces the naming of the learning area Arts and Culture. This subject forms part of the learning programme, General Studies, and is allocated two hours teaching time per week. In the Intermediate Phase Arts and Culture is replaced with Creative Art, forming part of General Studies and allocated two hours per week teaching time. It is also suggested that the generic integrated attempts of the current curriculum should be replaced by more distinct focus on Drama, Dance, Music and Visual Art (Final Report, 2009, p. 42-44). The report suggests that outcomes should be replaced with content, concepts and skills that are most appropriate to learning at different levels.

It is a relief to everybody involved with Arts education that our subjects are still there, because the entire review process propagates an emphasis on literacy, especially in English and Numeracy. At present bursaries awarded by the Department of Education (DoE) for teacher training are only awarded to students that choose Mathematics, Science and Technology as majors. The fear is that the Arts are often considered as an optional extra, regardless of the rich possibility for learning and acquisition of knowledge that is possible through the Arts (Rademaker, 2003, p. 17).

In his book, The Arts and the creation of Mind, Elliot Eisner writes about the Arts as a rich opportunity for learning. He describes a wide variety of possibilities for the practise and development of imagination. The total person, including intelligence, 
memory, skills and emotions can develop through Art-making. Few subjects can duplicate these experiences. The knowledge and ways of thinking that are cultivated through Arts education is seldom attained through other learning experiences. It leads to innovation and originality, which can be transferred and applied to other subjects (Eisner, 2002, p. 50). Ms M. le Roux, director for audience training at Artscape Cape Town writes about the importance of the Arts as a vehicle to transport knowledge in other subjects, in order to make knowledge more accessible and enjoyable for learners (Le Roux, 2007, p. 1).

Long ago, educators such as Dewey, Read and Lowelfeld wrote about the potential for learning that is possible through quality Visual Arts education. Hargreaves, Greene, Wright, Eisner and others, have elaborated on the undebatable learning that can occur in and through the Arts. This learning is manifested by the total development of the child (Westraadt, 2006, p. 5-8). Quality Visual Arts education provides opportunities for problem solving through experimentation and discovery, which opens unique channels for learning (Wright, 2003, p. 279). Cognitive skills that can be developed through rich and varied Arts education are organisation, problem solving, sequencing, ordering and sorting, critical analysis, planning, prediction, estimation, memory development, humour, concentration, decision making, flexibility, inventive thinking and imagination (Kear and Callaway, 2000, p. 142). Hickman, (2000, p. 147) writes about diverse forms of knowing which can include the aesthetic, scientific, interpersonal, formal and practical. These ways of knowing and learning that are possible through Visual Arts education activates the senses, intellect and emotions. It is often non-verbal and difficult to measure using conventional instruments or tests.

Human intelligence is multi-faceted and there are individual variations in learning. Arts education provides for visual, auditory, kinaesthetic, verbal and enactive modes of comprehension and can lead to higher levels of literacy (Robinson, 1993, p. 25). Visual thinking bridges the two hemispheres of the brain. Modern learners are absorbed by information that is presented visually. Visual literacy develops critical and independent thinking (Knight, 2004).

Added to the various intelligences, cultural background and the frame of reference of learners are also vastly different. Culture can play an important role in learning style. Arts education provides opportunity for the development of individual thinking. This contributes to respect for diversity and prevents stereotyping. Critical and creative thinking, alertness, openness, and acceptance of others are of the qualities that can be attained (Greene, 1995, p. 179). The Arts provide an environment and opportunity that empowers diverse learners to participate in activities which develop observation and expression (Kear et al., 2000, p. 135).

There are concerns amongst Arts education practitioners about the effect of yet another review and the impact the changes might have on the quality of Visual Arts education. 


\section{Change is upon us once again}

As mentioned in the beginning of this paper, C2005 has been reviewed and major changes can be expected. A certainty is the increase of time allocated to languages, mathematics and science. This brings to mind the critique by Chapman (2004, p. 12) of the 'No Child Left Behind Act' of the USA as follows; the core academic subjects, previously called the three R's (Reading, wRiting and aRithmetic) are granted most time and funding, while the Arts are often regarded as an extra, used as a bribe or reward. Wright (2003, p. 39) states that artistic modes of knowing are overlooked where the three R's are primary.

It is clear from the report tabled by the task team that the learning area Arts and Culture will cease to exist and it seems that distinct teaching in the Art disciplines, will be re-instated (Final Report, 2009, p. 42-44). Exactly what will happen to Visual Art remains uncertain until the final policy is published. Drafts of the new policy documents were made available for comment by stakeholders in September 2010. As Visual Arts education is often on uncertain ground, a great concern for Arts educators is what will happen with the teaching of quality Visual Arts education.

In an article in the Cape Times, Le Roux (2007, p. 11) mentioned that the participation in Arts and Culture by all learners can contribute to the development of critical thinking, imaginative skills and creativity. This requires skilled Arts Educators who are able to communicate the Arts to all South African learners. Ms Le Roux stresses the necessity of skills-based Arts education in the General Education and Training Band to ensure proper articulation into the Further Education and Training specialised Art subjects. It could be argued that worldwide, the low status and time allocated to the Arts in education in comparison with the other educational imperatives such as Sciences, Mathematics and Technologies points to the general lack of appreciation of the contribution of the humanities to the development of people as social, cultural, productive and collaborative citizens. Ms Le Roux cites Psilos (2002, p. 1), who draws attention to the compelling advantages of Arts education developing "competencies necessary to become economically self-sufficient over the long term" and the potential impact of Arts education on workforce preparation. There is mention of the success of Arts education programmes, especially amongst youth at risk; through increasing academic performance, reducing absenteeism, increasing self-esteem, interpersonal skills, positive attitudes towards work, creative thinking, problem-solving and communication skills and the ability to work without supervision.

Prior to 1994, and the change in South Africa to an inclusive democratic government, Arts education was not available to the majority of learners in South Africa. Music and Visual Art tuition was primarily offered at the schools formally reserved for 'white' students and at some 'coloured' schools. Schools from the ex-department of education and training for black learners provided tuition in Arts and Crafts. For the rest, learners who could afford it studied Music and Dance privately outside of school time. Children from higher socio-economic brackets, who were exposed to the Arts through other sources, such as families and communities, reaped the benefits of these activities; 
children lacking these resources lost out on the educational advantages that Arts education provides. The inclusion of Arts and Culture as a compulsory learning area for all learners in the General Education and Training Band is a wonderful opportunity for all to empower themselves through participation in the Arts (Le Roux, 2007, p. 11).

Who are to facilitate the learning through Visual Arts education that is such an important part of the holistic development of pupils in the primary school that can lay a foundation for building on in the Further Education and Training (FET) band and the focus schools that have been started by the DoE?

\section{Higher education}

At the level of higher education, the former teacher's diploma had to be revised to provide for the training of teachers in a BEd degree (Adler et al., 2002, p. 19, 33). The White Paper on Higher Education (RSA, 1997) recommended that teacher education be unified in a system of higher education. Five principles were recommended as a basis, namely: global and national relevance, learner centeredness, professionalism, cooperation and collegiality and innovation. A Committee on Teacher Education and Policy (COTEP) put together norms and standards (1995), in accordance with the national policy sanctioned by the minister of education in 1995 (Pretorius, 2004, p. 114).

Future curricula were expected to be congruent with these standards as set out in the Higher Education Qualifications Framework (HEQF). The transformation was based on equality, human dignity, social justice and basic human rights. The approach to education and training, lifelong learning and outcomes-based delivery was organised on the basis of the qualifications framework (Pretorius, 2007, p. 44-45).

Norms and standards identify seven roles of the teacher as mediator of learning, interpreter and designer of learning programmes, assessor, lifelong learner, area/ subject/discipline/phase specialist, active in the community in citizenship and pastoral roles, leader, administrator and manager (Du Plessis, 2007, p. vi-ix).

New structures for quality assurance, such as the Committee for Higher Education (CHE), the Higher Education Quality Committee (HEQC), and the South African Qualifications Authority (SAQA) were put in place. Substantial reform was enforced in a very short period of time (Pretorius, 2007, p. 44-45).

Since 2001 pre-service teachers at various Universities in South Africa have had the changed school curriculum built into their subject didactics for the learning areas, as expounded in the National Curriculum Statement for C2005 (National Curriculum Statement. Grade R-9 (Schools) Policy, 2002). However, at this point in time, teachers who have had the didactics of the National Curriculum Statement taught as a formal part of their BEd degree comprise approximately $20 \%$ of the workforce currently teaching in schools. 


\section{Teacher training in Visual Art}

My concern about Visual Arts education and the learning opportunities as a result of quality Arts education led to an investigation of the curricula for teacher training in Arts and Culture. The curricula for Arts and Culture, especially Visual Art of four South African and one foreign university were compared. Universities: 1, 2, 3 and 5 are South African, while university 4 is in a foreign country.

The yearbooks of the universities were available and opened on the Internet. Some of these documents for the BEd degree were very comprehensive, adding up to over 300 pages, whilst others were very basic, consisting of only four pages.

From these yearbooks, undergraduate curricula and all the information that pertained to Visual Arts education, and in some cases Arts and Culture, for the four years of study was extracted and is presented in table form in this paper. The purpose of this extraction is to compare what is offered at other universities for the BEd degree in Arts education.

Anonymity of the universities consulted is preserved for the purpose of this paper. 


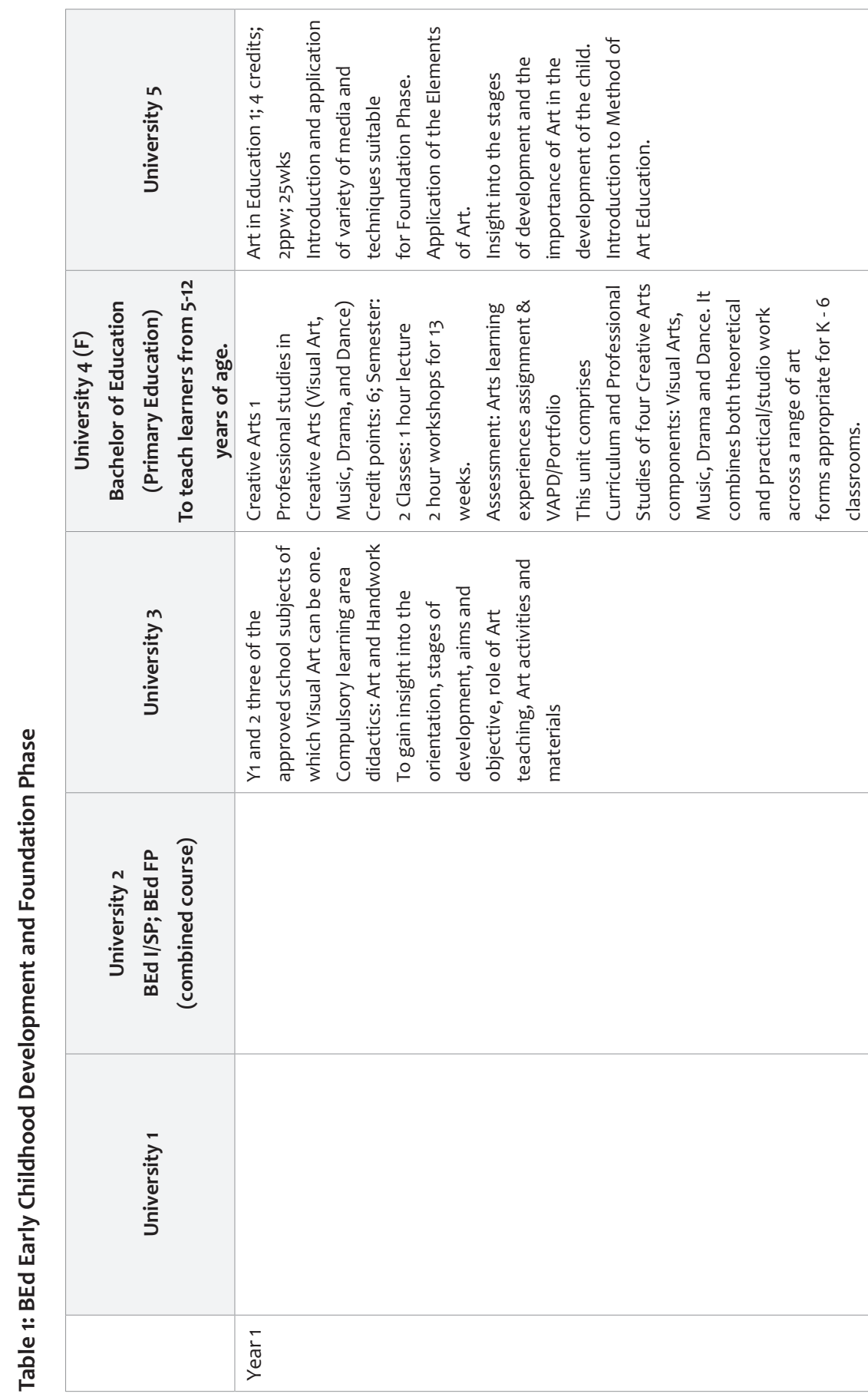




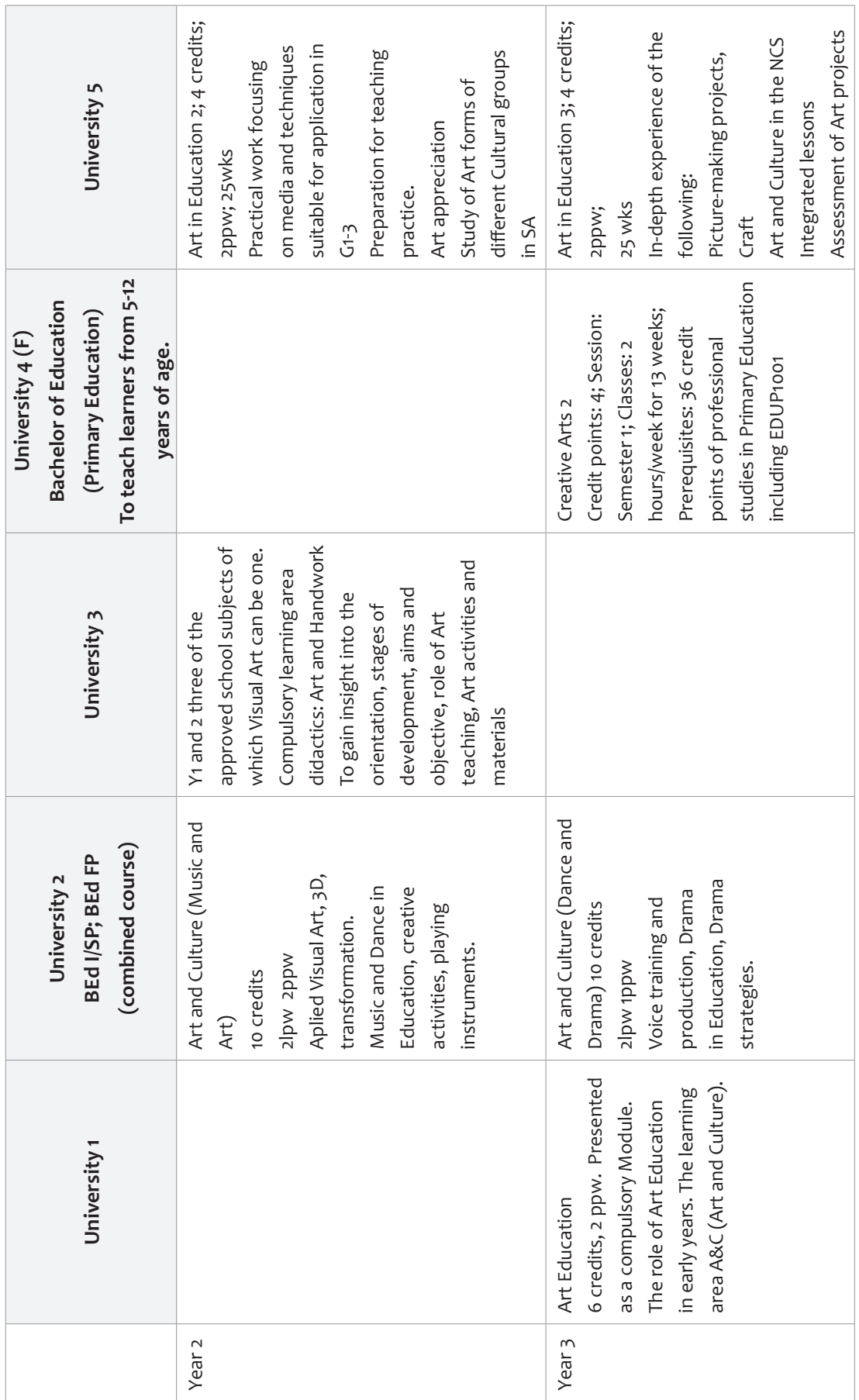




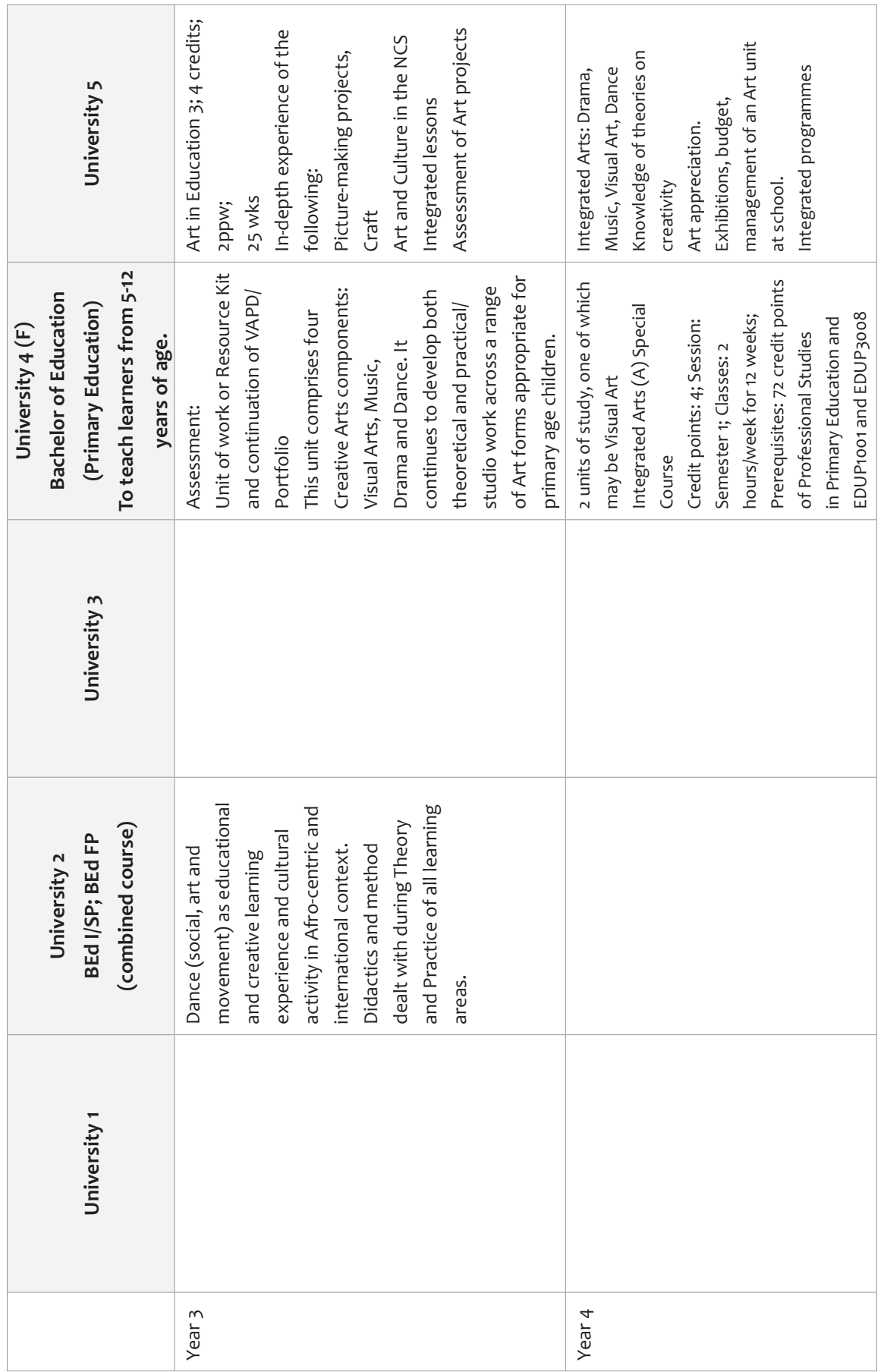




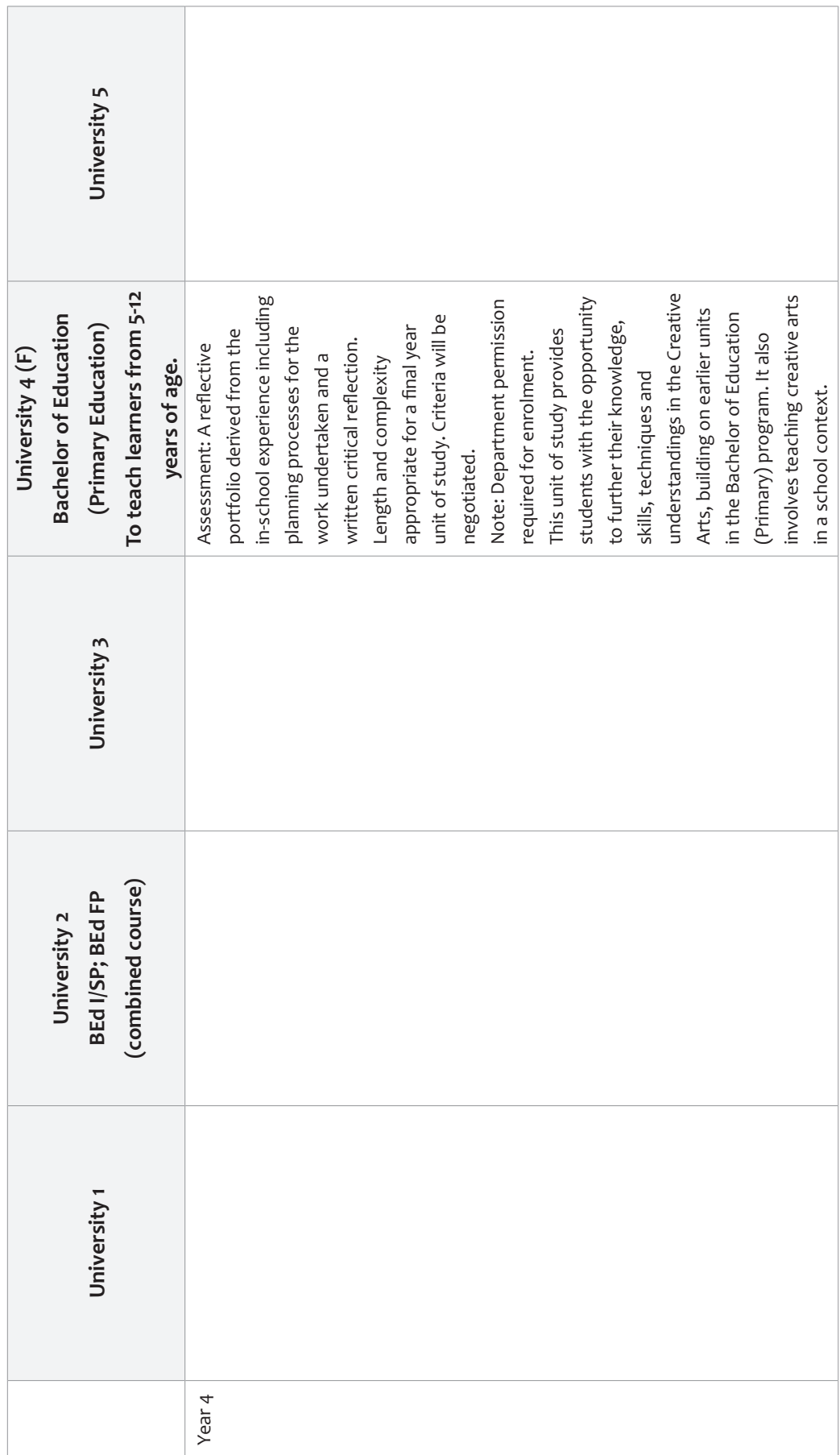




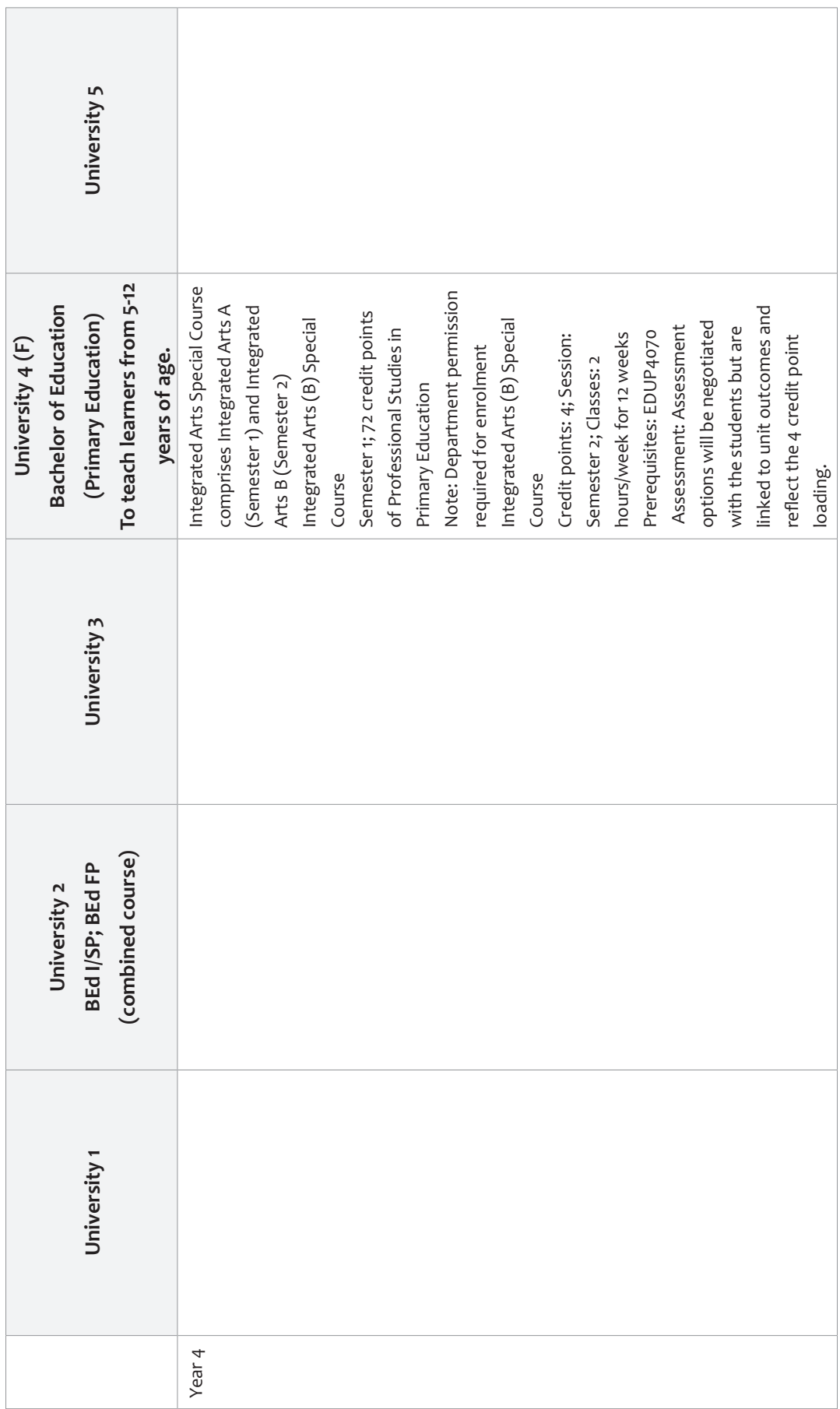




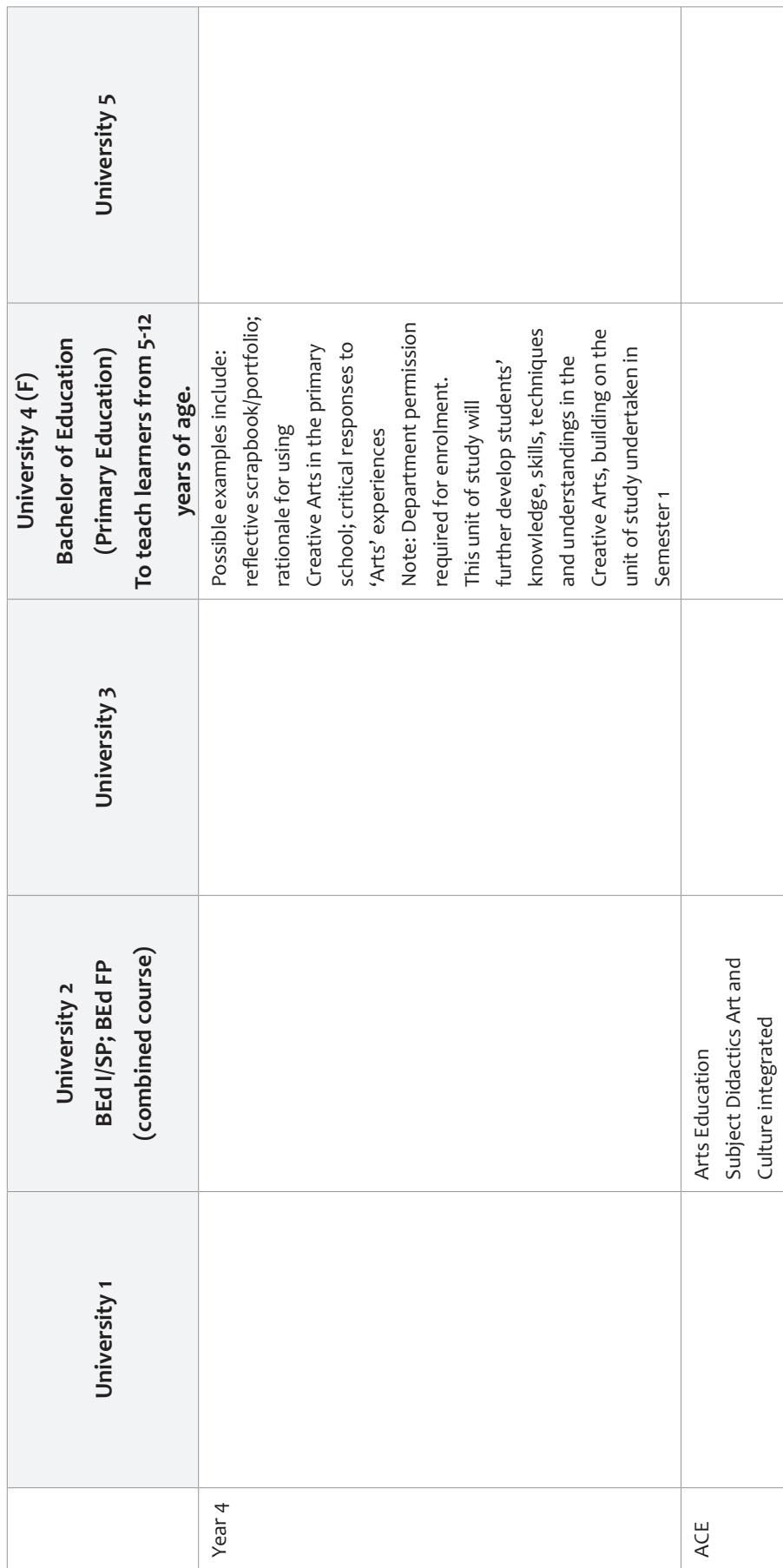




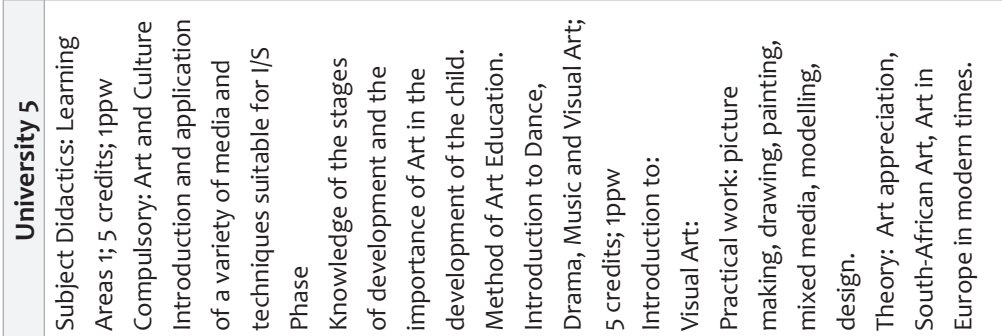

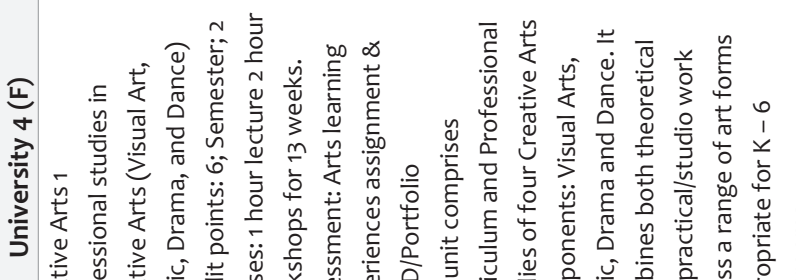

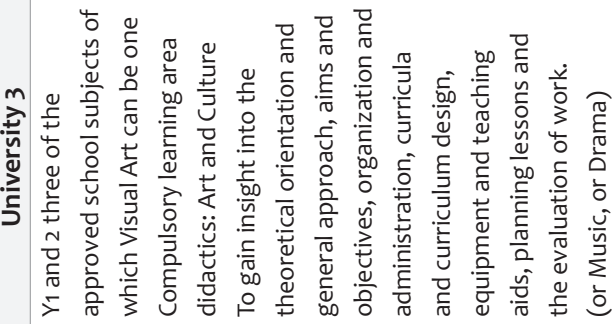

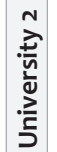

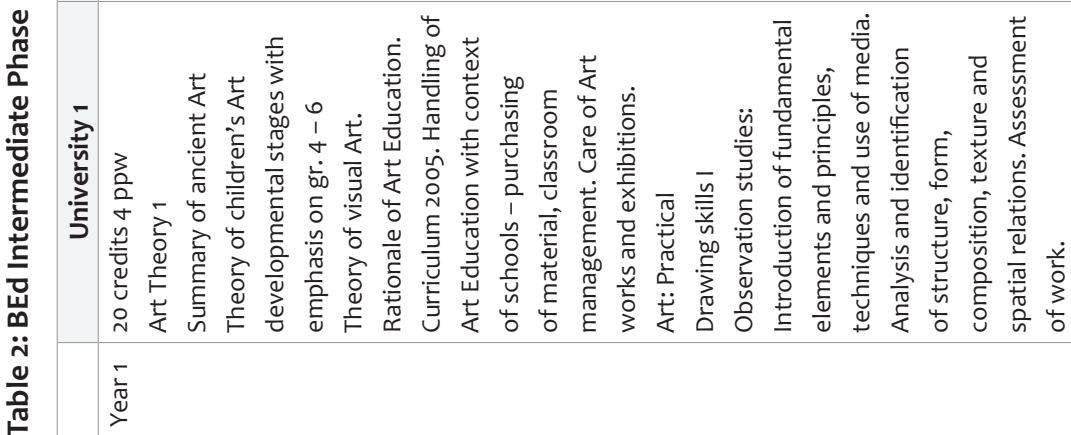




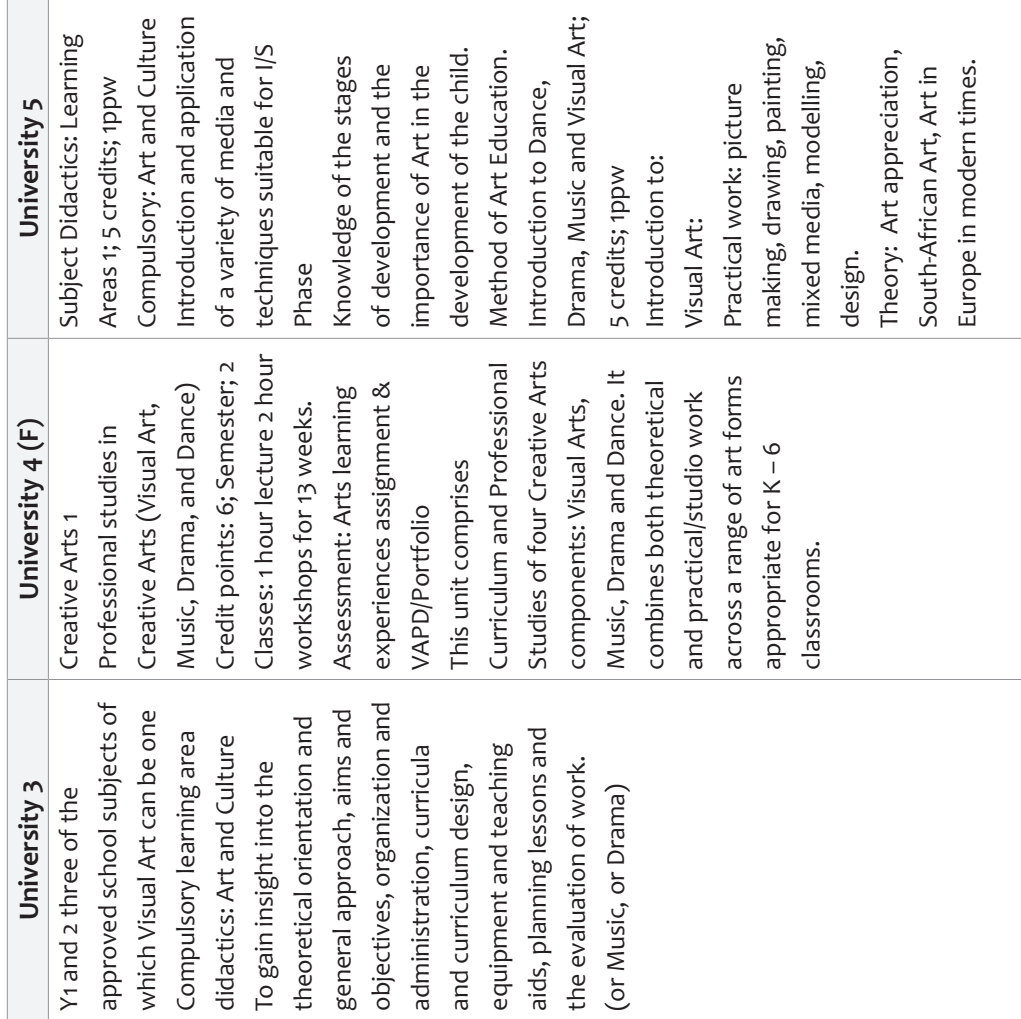

ֻับ

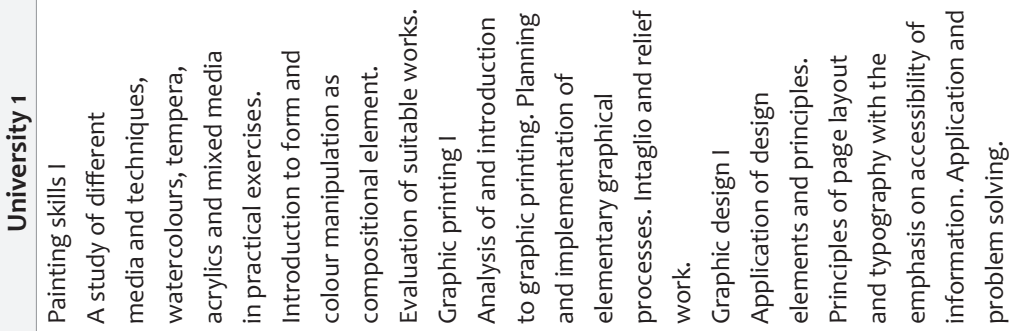
들 


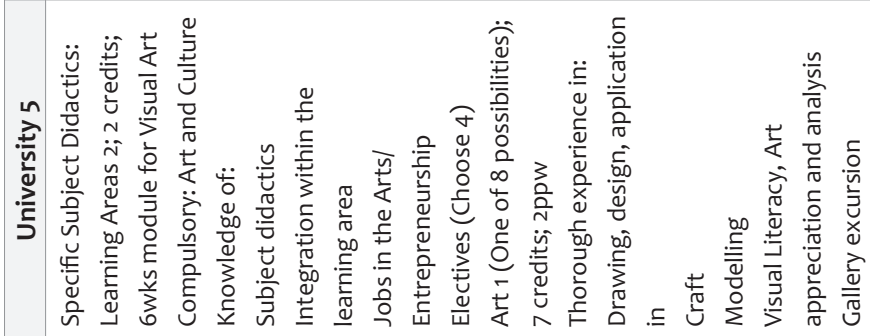

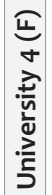

屯ั0

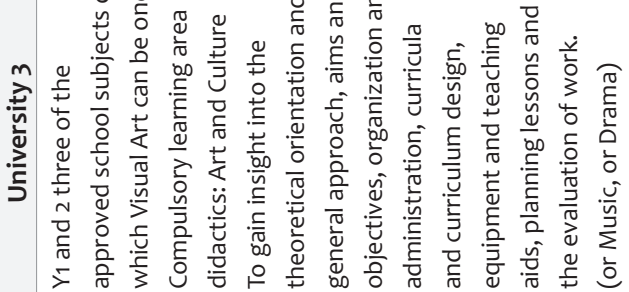

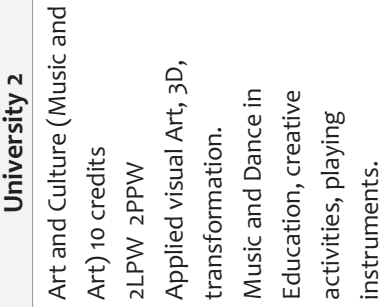

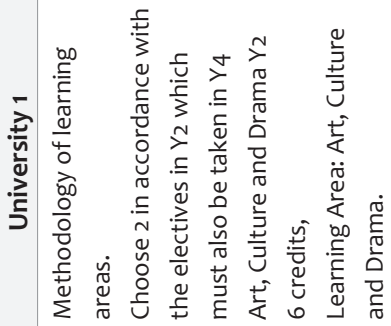

文 


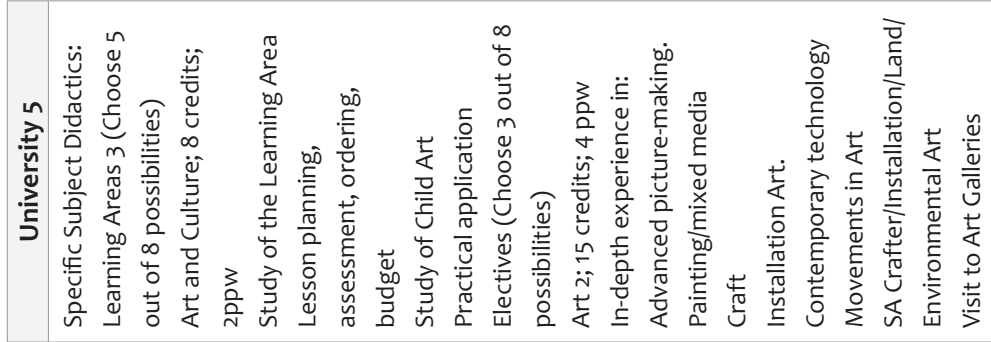

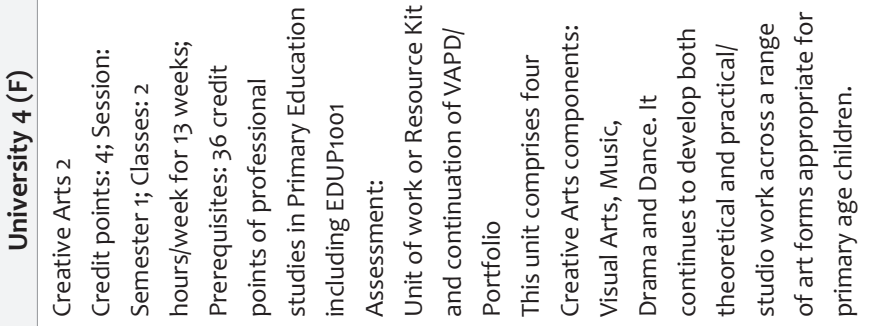

:

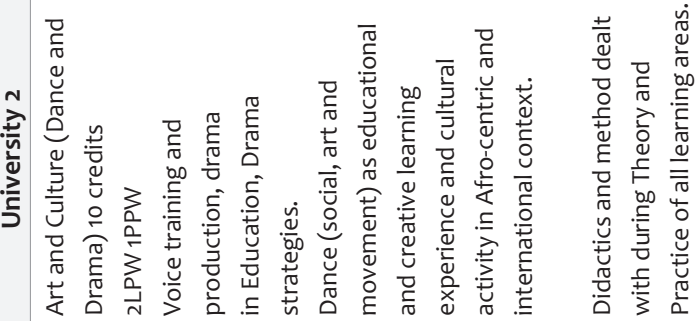

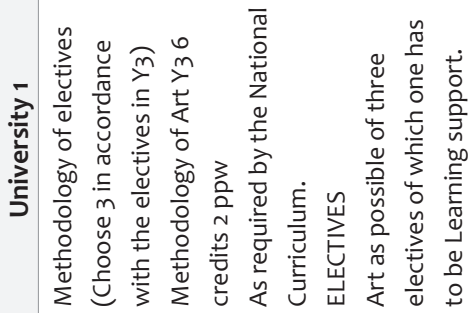

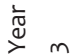




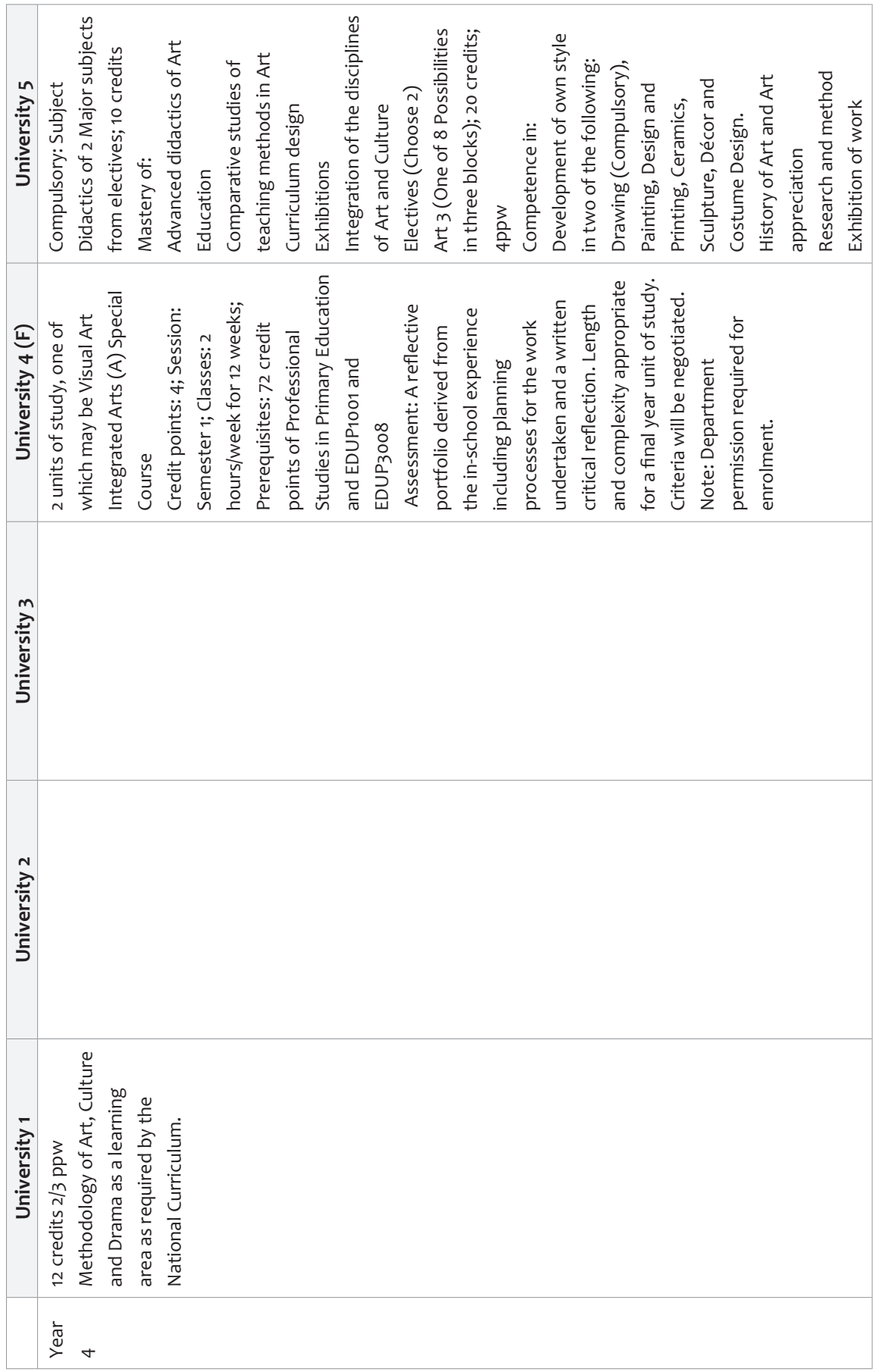




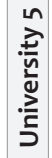

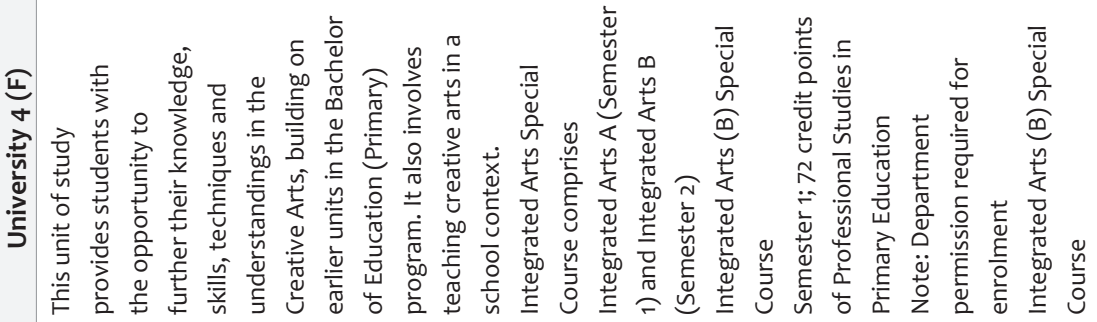

$\overbrace{\substack{n \\ \frac{n}{2}}}^{\frac{n}{2}}$

文

$\stackrel{\frac{1}{\pi}}{\stackrel{2}{~}}$ 


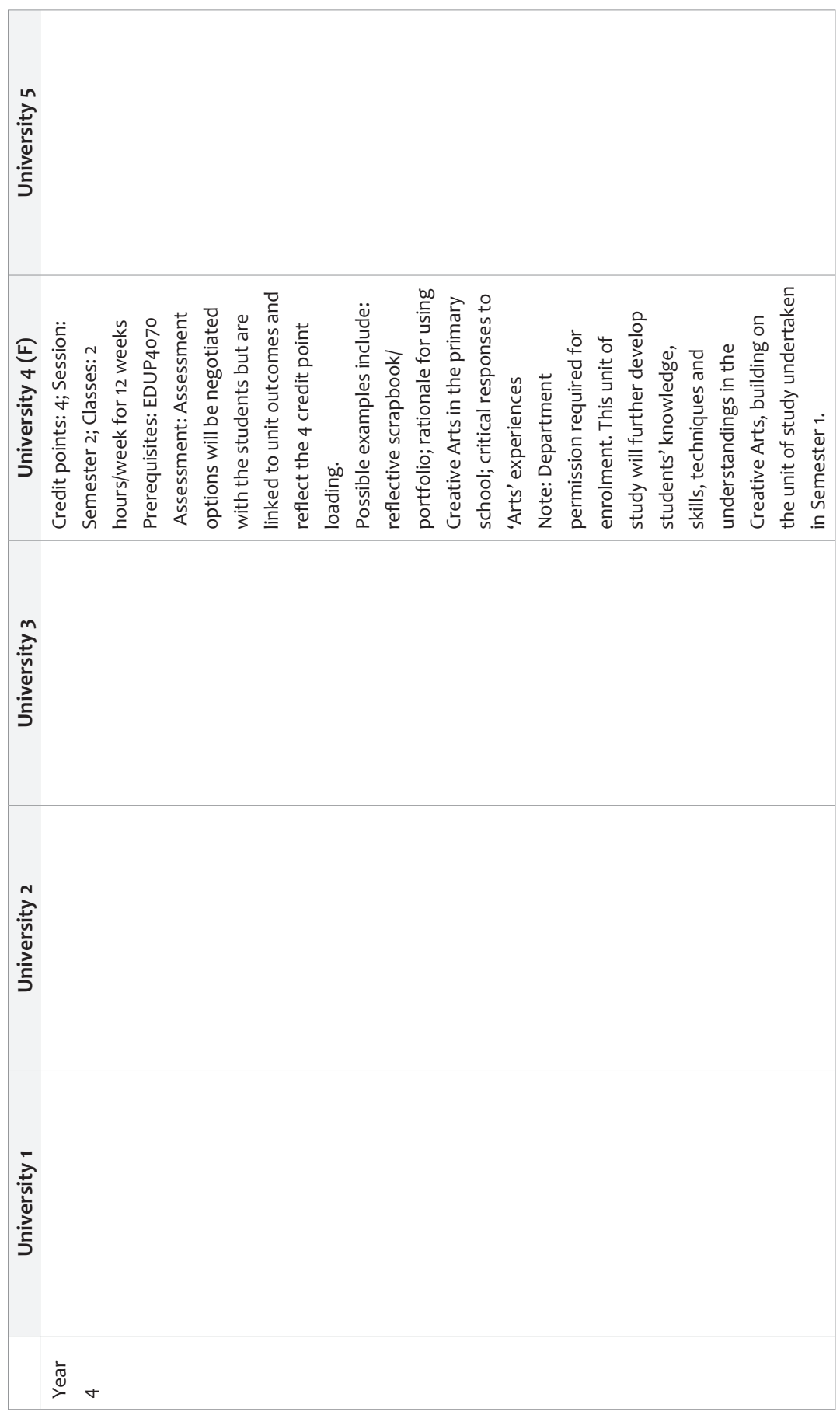



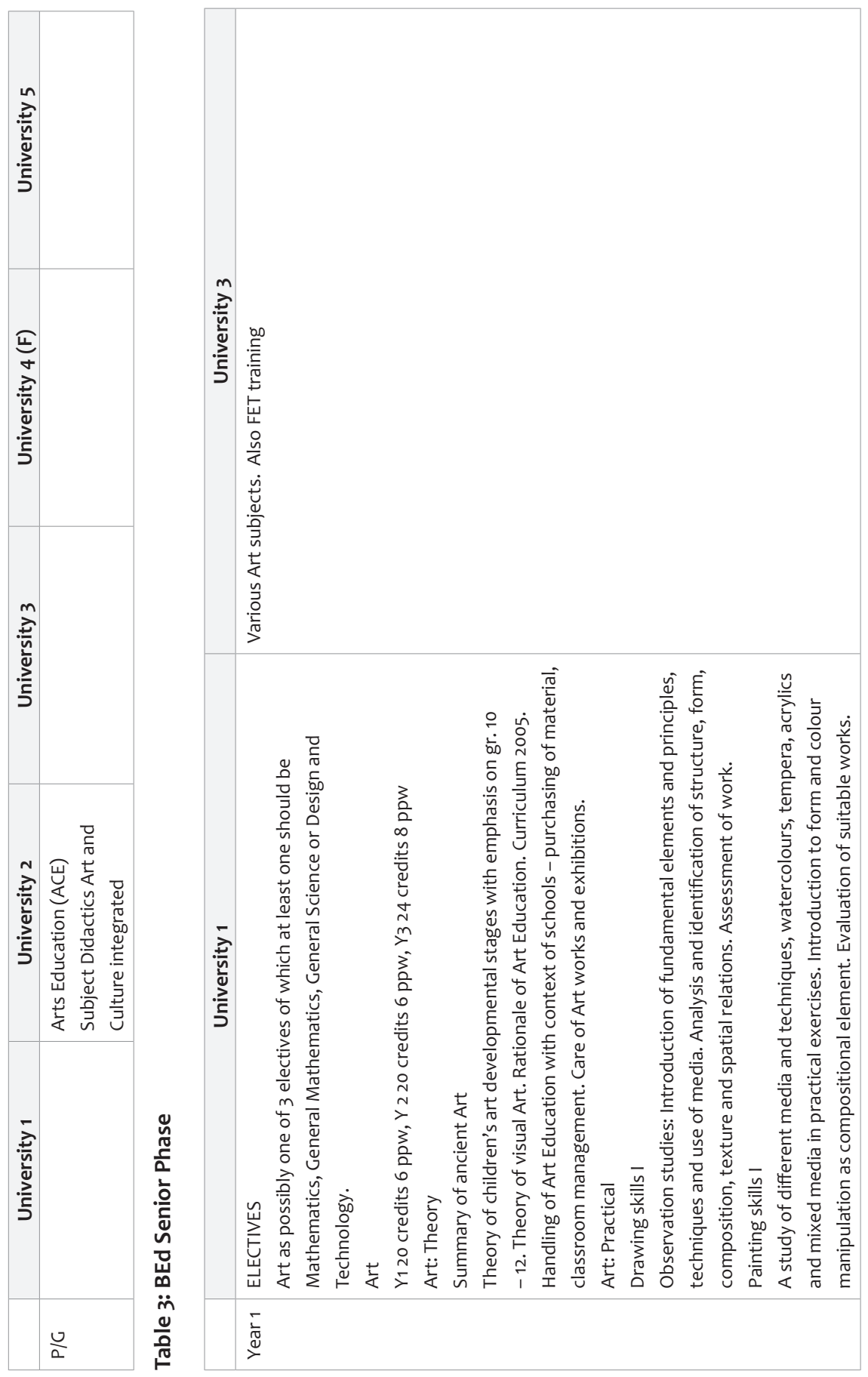


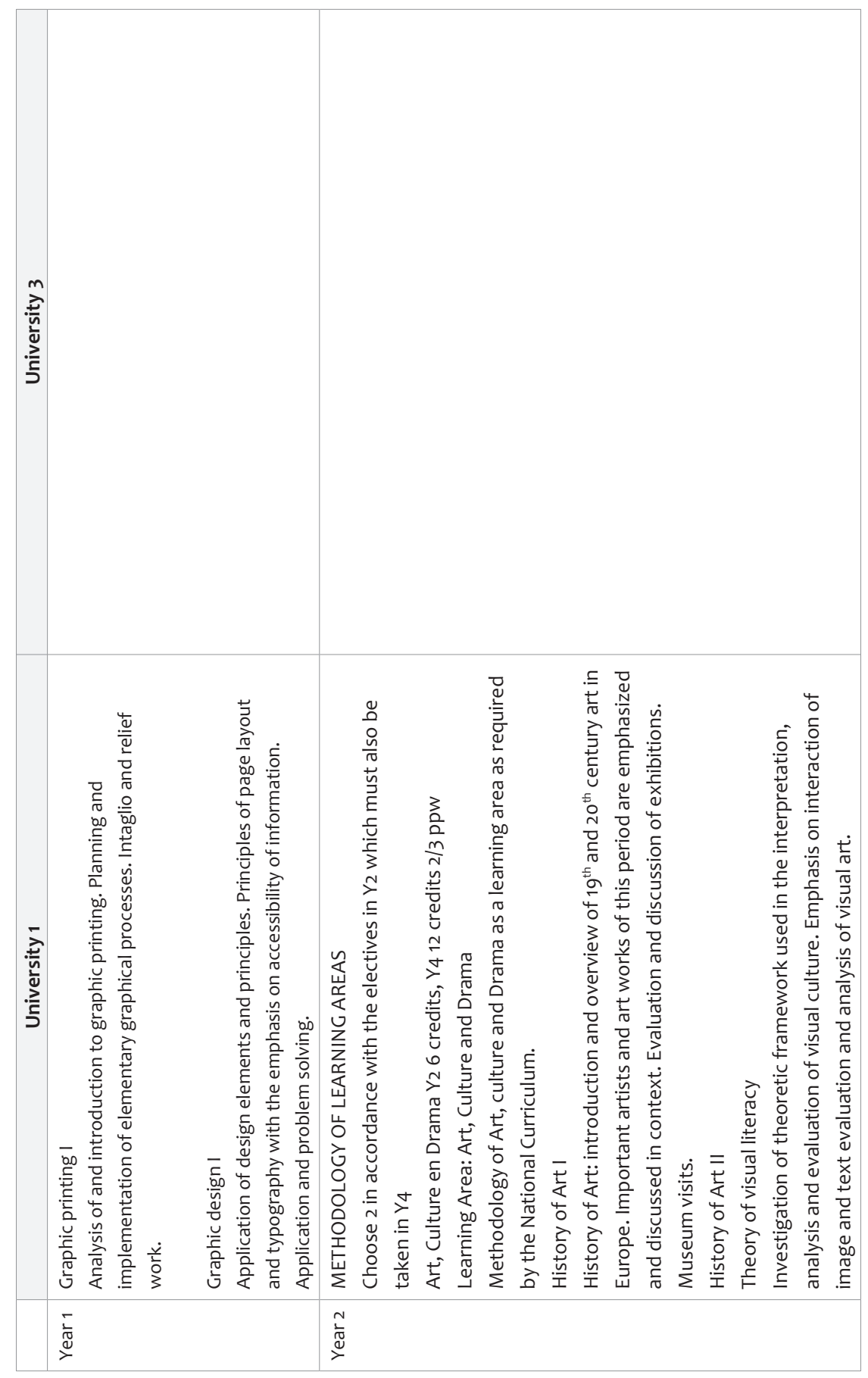




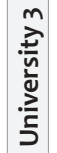

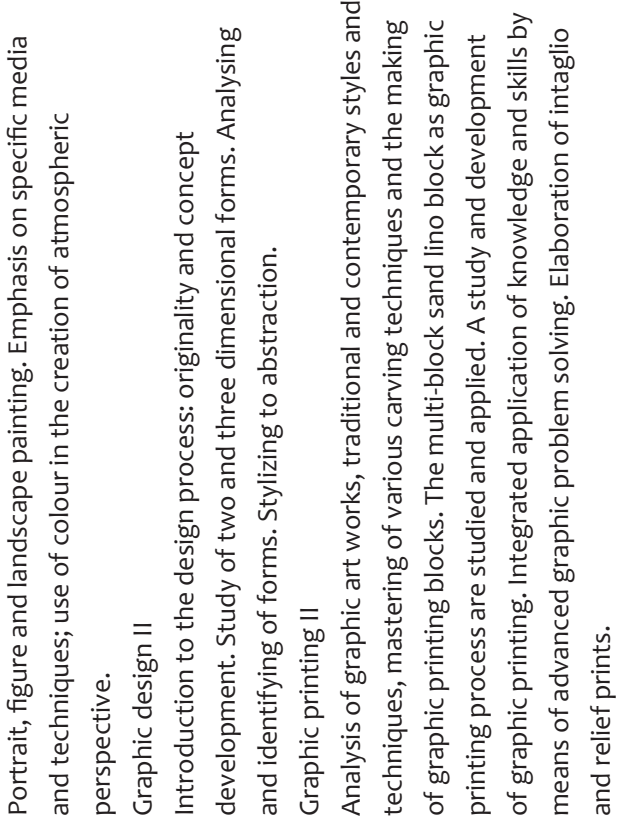

$\stackrel{\frac{1}{2}}{\frac{1}{2}}$ 


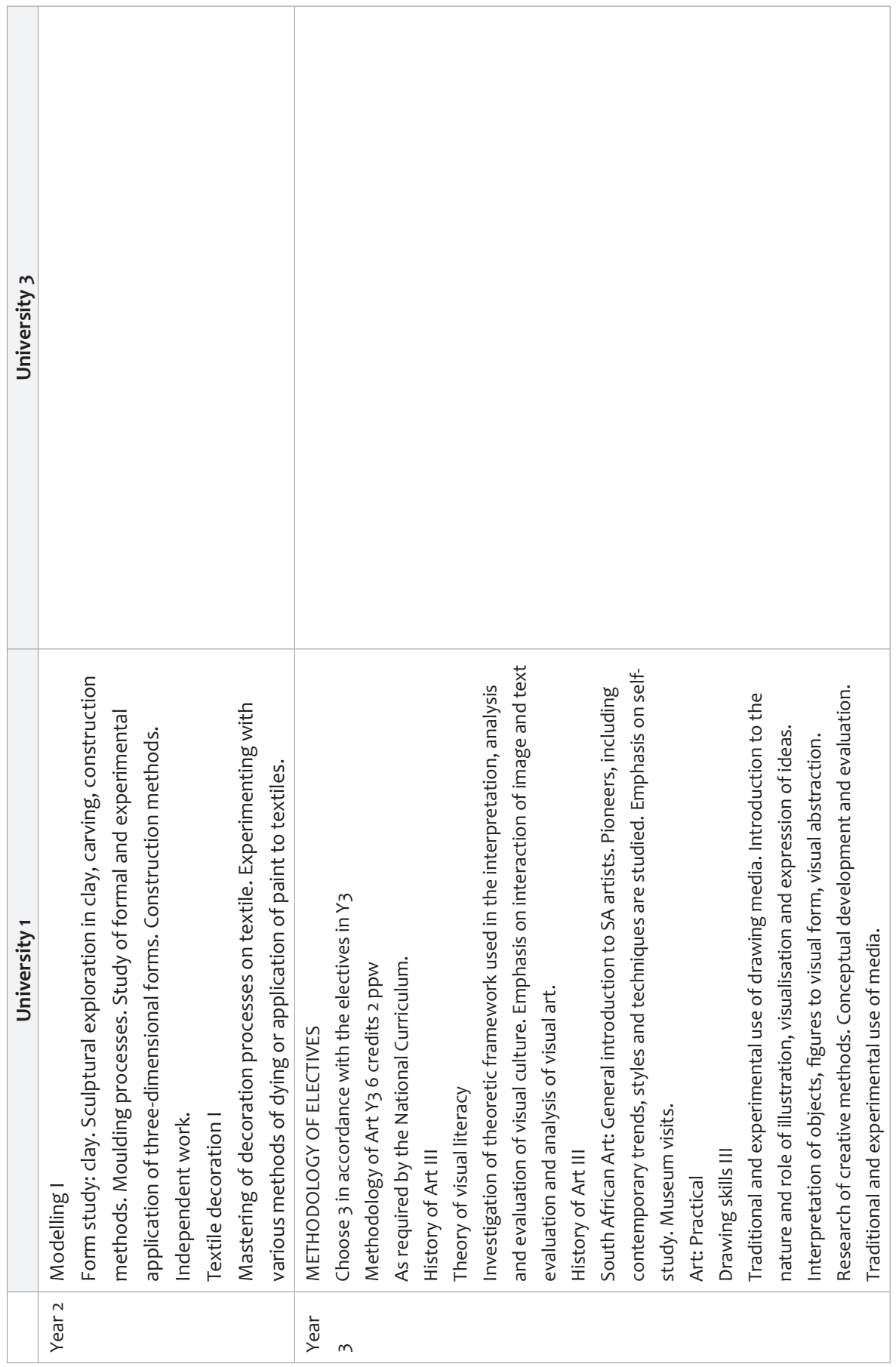




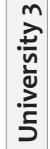

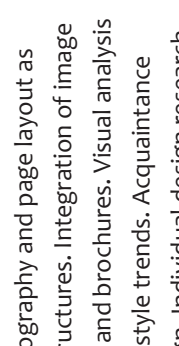

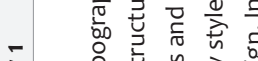

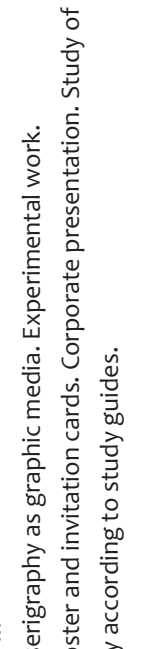

$\dot{\tilde{n}} \stackrel{\frac{\pi}{\bar{\sigma}}}{\bar{\sigma}}$

$\stackrel{\frac{n}{\bar{N}}}{\frac{\bar{d}}{3}}$

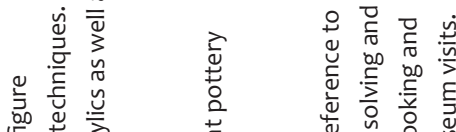

on

离

늉

ठ․ है

政

ปั

- 4

을

पू $\frac{\pi}{\pi}$ है

टा है

व

艺艺

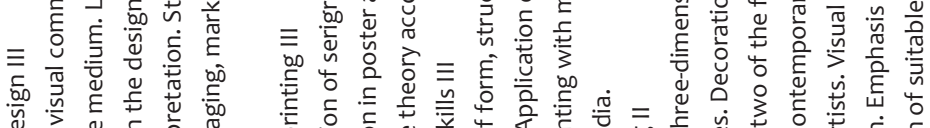

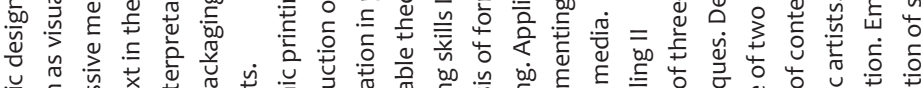

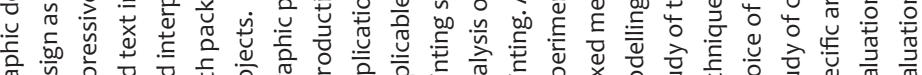

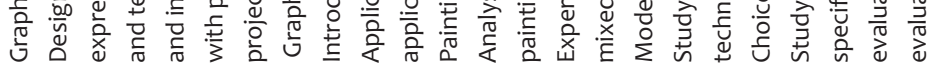

$\stackrel{\frac{1}{0}}{\stackrel{1}{2}} m$ 


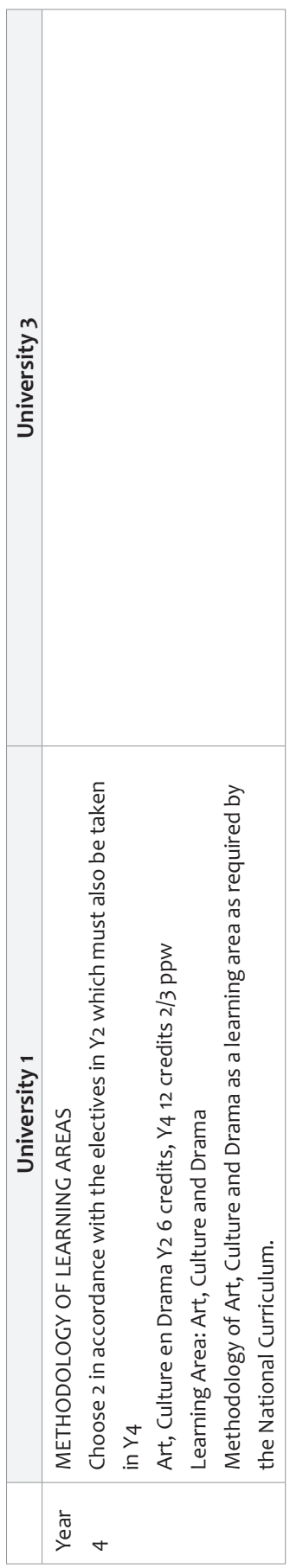




\section{Summary and discussion}

The curricula for teacher training in Visual Art and in some cases Arts and Culture as offered by five universities is summarised under numeric headings and discussed briefly.

Blank spaces indicate other courses, mainly Education, Professional Studies, Academic Literacy, Languages and Mathematics, which are not considered for the purpose of this study.

\section{University 1}

The degree is divided into three possibilities, namely: Foundation Phase, Intermediate Phase and Senior Phase. This is the only university in the study that offers the Senior Phase as a separate option.

For the Foundation Phase, Arts education is only presented in year 3 as a compulsory module. The learning area Arts and Culture is studied.

For Intermediate and Senior Phases there is a very comprehensive programme in Visual Arts education with a theoretical and practical component aimed at the age group falling in that phase. The NCS and learning areas are dealt with in methodology. Courses are offered over the course of a year. Practical work, as well as the history and theory of the Arts form part of the elective that is to be studied as an area of specialisation.

\section{University 2}

The degree is combined for Foundation and Intermediate Phases.

For year 2 there is Arts and Culture (Music and Art), which includes applied Visual Art, three-dimensional and transformation.

Didactics and method is dealt with during theory and practice of all the learning areas. Visual Art is not offered as an area of specialisation at undergraduate level.

\section{University 3}

One degree is offered for all phases. During year 1 and 2 three of the approved school subjects of which Visual Art can be one, is offered. The compulsory learning area didactics: Art and Handwork has as its aim the gaining of insight into the orientation, stages of development, aims and objective, role of Arts teaching, Arts activities and materials. Visual Art is not offered as an area of specialisation.

\section{University 4}

This is a foreign university of which an Outcomes Based curriculum is followed in schools. Similar to South Africa the Arts disciplines (Dance, Drama, Music and Visual Art) are combined as one learning area.

The BEd is offered for the teaching of primary school children (ages 5-12) and a separate degree for the teaching of secondary school children. 
In year 1 Professional Studies combine the Art forms. These are offered as semester courses. Theoretical and practical/studio work across a range of Art forms appropriate for K-6 classrooms is offered.

Year 3 offers a succession of the above, but the emphasis is now on work for primary school learners. It is offered in semester courses.

During year 4 there is continuation of the above in semester courses. During this year there is room for reflection after the in-school experience.

Throughout the training the Creative Art is presented in an integrated manner.

\section{University 5}

The BEd degree is presented for Foundation Phase and Intermediate/Senior Phase separately. Visual Art and Subject Didactics are offered from year 1 through to year 4. Students following Intermediate/Senior Phase can take Visual Art as an elective specialisation through to fourth year level. The Subject Didactics of all learning areas have to be completed under a separate subject code. Practical work is presented in a wide range of media and techniques suitable for primary school level. Art History Method and Theory are included.

It is clear that the majority of Universities have structured the courses in Visual Arts education according to the current curricula in schools. What is the role of Higher Education Institutions in an ever-changing scenario?

\section{The role of Higher Education Institutions (HEls)}

How much should the ever-changing school curricula influence what is taught in pregraduate level of university programmes?

It is clear from the curriculum outlines above that the BEd curricula for the universities in South Africa, which were selected for this comparison, have been designed with the curriculum that is presently followed in schools as a guideline for the course "Subject Didactics and Method". How is the review of C2005 and the subsequent new Curriculum and Assessment Policy document going to influence Universities in their training of teachers for their future careers in schools in this country?

Wolhuter (2007, p. 217) suggests that overt national governmental involvement and bureaucratic administration could impact negatively on the academic profession. Reshaping the current model of education, that is informed by thorough research could redress and ensure that universities remain the citadel from where the wise could give counsel.

Higher education has to identify the learning needs of private and public sectors and reorganise curricula to match desired outputs. The mode of delivery should be dynamic, flexible and responsive to the demands and needs of the country (Gravett et al., 2004, p. 141). It is important that there should be cooperation between HEls and practice schools. Reflective inquiry is important in assigning meaning to teaching 
and the practical activity of establishing whether these meanings are realised in the shaping of teacher-education programmes (Van Huizen et al., 2005, p. 285, 278).

Teachers need to have an understanding of the subject matter that they need to teach to ensure quality and meaningful Visual Arts education (Darling-Hammond et al., 2005, p. 5). Furthermore, they need to understand the development of children and how Visual Art education can support this development. Learning and development are embedded in cultural contexts. Knowledge of the subject matter and curriculum goals of Visual Arts education, knowledge of how to teach Arts lessons, knowing how to assess Arts projects and how to manage an Arts classroom effectively is required. Through the teaching of Arts lessons teachers will learn more about Visual Arts practice.

Candidates for the teaching profession need a body of knowledge as foundation. Courses should be coherent and build on one another. There should be opportunities for practice teaching which are tied to the learning of constructs and be provided with examples of what good teaching looks like and consists of (Baratz-Snowden, 2005, p. 10).

With regards to Visual Arts education there are questions about the generalist vs. the subject specialist and the impact on quality Visual Arts education. Most students entering the BEd programme have not experienced quality Visual Arts education at school level. With two or more majors forming part of the BEd final year there is less time for the nurturing into the art of teaching Art, which requires time to practice skills, time to focus and reflect on the potential for rich and varied learning that is possible through quality Visual Arts education. Should the voice of the teachers themselves, when asked how they believe they could be practically assisted, not be heard when they requested that specialisation in one learning area should be encouraged? Such assistance could deepen their knowledge and teaching skills and enable generalist teachers to teach at least some subjects properly (Johnson, 2005, p. 7).

The Final Report from the review task team suggests that the generic integrated attempts of the current curriculum should be replaced by a more distinct focus on Drama, Dance, Music and Visual Art (Final Report, 2009, p. 2-44). The report suggests that outcomes should be replaced with content, concepts and skills that are most appropriate to learning at different levels.

HEls should proactively be involved in the design of new curricula, from an expert and subject specialist point of view, so that their graduates entering schools are informed and enlightened and not necessarily be dictated by bureaucratic procedures.

\section{Conclusion}

The principles for the teaching of quality and meaningful Visual Arts education remain the same throughout school systems. The uncertainty with regards to the new school curriculum has impacted negatively on the ratio of graduates choosing the Arts as majors. This fact has been aggravated by the allocation of bursaries only to students with Mathematics, Science and Technology as the chosen majors. The importance of 
Literacy and Numeracy at school level can never be disregarded, but Visual Literacy is an important part of being literate. Educators involved in Visual Arts education cannot sit back and allow a decline in the training of Visual Arts educators. The current shortage of well-trained Visual Arts educators should be addressed and the quality of Visual Arts education over the entire spectrum assured to allow all members of future generations in schools to experience the rich variety of learning opportunities that are possible through quality Visual Arts education.

\section{Bibliography}

Adler, J. \& Reed, Y. (Ed.). (2002). Challenges of teacher development. An investigation of take-up in South Africa. Pretoria: Van Schaik.

Bloch, B. (2009). The toxic mix. What's wrong with South Africa's schools and how to fix it? Cape Town: Tafelberg.

Darling-Hammond, L. \& Baratz-Snowden, J. (2005). A good teacher in every classroom. Place of publication? Town: Jossey-Bass.

Chapman, L.H. (2004). No child left behind in Art? Arts Education Policy Review, 106(2), 3.

Du Plessis, P., Conley, L. \& Du Plessis, E. (2007). Teaching and learning in South African schools. Pretoria: Van Schaik.

Eisner, E.W. (2002). The Arts and the creation of mind. Place of publication?: Yale University Press.

Gravett, S. \& Geyser, H. (Ed.). (2004). Teaching and learning in higher education. Pretoria: Van Schaik.

Greene, M. (1995). Releasing the imagination. California: Jossey-Bass.

http://www.yearbooks from 5 Universities - invalid website address and insufficient information.

Hatton, K. (2003). Multiculturalism: Narrowing the gaps in Arts education. Race, Ethnicity and Education, 6(4), 357.

Hickman, R. (Ed.). (2000). Art education 11 -18. Meaning, purpose and direction. London: Continuum.

Johnson, S. (2007, June). The "Arts and Culture" policy vulture. Paper presented at the $14^{\text {th }}$ International Learning Conference. Johannesburg, South Africa.

Jolley, R.P., Fenn, K. \& Jones, L. (2004). The development of children's expressive drawing. British Journal of Developmental Psychology, 22(4), 547-563.

Kear, M. \& Callaway, G. (2000). Improving teaching and learning in the Arts. New York: Falmer Press.

Knight, L. (2004). The critical eye: How visual literacy has become a vital tool for negotiating modern culture. Paper presented at the Literacies and Numeracies Exposed Conference, University of Canberra, Town, Country. 
Le Roux, M. (2007, 15 November). Neglected area reflects apartheid's legacy. The Arts are vital to children's education. The Cape Times, page numbers?.

Republic of South Africa. (2002). National Curriculum Statement. Grade R-9 (Schools) Policy. Government Gazette, 23406(443) 31 May. Pretoria: Government Printers.

NCC Arts in Schools project. (1990). The Arts 5-16 practice and innovation. Essex: Oliver \& Boyd.

Pretorius, F. \& Lemmer, E. (2004). South African education and training. Transition in a democratic era. Braamfontein: Hodder \& Stoughton.

Rademaker, L.L. (2003). Community involvement in Arts education: A case study. Arts Education Policy Review, 105(1) 16-23.

Rademeyer, A. (2009, 25 November). Uit met die oue, in met die nuwe. Die Burger, page number?

Report of the Task Team for the Review of the Implementation of the National Curriculum Statement. Final Report presented to the Minister of Education, October 2009. http://www.pgwc.gov.za [2009/11/10]. INVALID WEBADDRESS

Snow, C.S. \& McLaughlin, T.F. (2005). The effects of teaching perspective in a structured and systematic way on still life drawing of Elementary Students. An empirical study. Educational Research Quarterly, 28(3), page numbers.

Van Huizen, P., Van Oers, B, \& Wubbels, T. (2005). A Vygotskian perspective on teacher education. Journal of Curriculum Studies, 37(3), 267-290.

Western Cape Provincial "Arts and Culture" Task Group. (1995). Arts Education Policy Discussion Document. Draft 2.

Western Cape Education Department: Tradeworld reference Ed 15236. (INSUFFICIENT INFORMATION - if this is all that is available; rather include in text and omit from reference list.)

Westraadt. G. (2006). Die onderrig van Visuele Kuns. Stellenbosch: Universiteit van Stellenbosch.

Westraadt, G. (2007). Facilitating a rich variety of learning opportunities through Visual Art. MEd thesis. Cape Town: CPUT.

Wolhuter, C.C., Lemmer, E.M. \& De Wet, N.C. (Ed.). (2007). Comparative education. Education and contemporary issues. Pretoria: Van Schaik.

Wright, S.K. (2003). The Arts, young children and learning. Boston: Allyn and Bacon. 